\title{
Immediate postoperative care
}

\author{
Ian Adatia, ${ }^{1}$ Maurice Beghetti ${ }^{2}$ \\ ${ }^{1}$ Pediatric Cardiac Critical Care Program, Stollery Children's Hospital, University of Alberta, Edmonton, \\ Canada and ${ }^{2}$ Pediatric Cardiology Unit, Children's Hospital, Department of the Child and Adolescent, \\ University of Geneva, Geneva, Switzerland
}

Keywords: Pulmonary hypertension; congenital heart disease; postoperative intensive care; pulmonary hypertensive crisis; nitric oxide

T HE FUNCTIONAL AND STRUCTURAL STATUS OF THE pulmonary vascular bed plays a pivotal role in the presentation and outcome of the child with congenital cardiovascular disease. However, it is in the immediate postoperative period that the child is most vulnerable to a sudden or sustained increase in pulmonary vascular resistance. Following surgery for congenital cardiac disease pulmonary vascular reactivity is heightened and vasospastic stimuli may result in sudden increases in pulmonary arterial pressure and resistance resulting in acute right heart failure, tricuspid regurgitation, systemic hypotension, myocardial ischemia and increased airway resistance. These episodes, called pulmonary hypertensive crises, may be lethal events. Furthermore, mildly stimulating events precipitate similar crises, and the crises tend to last longer and cluster. $^{1,2}$

Clearly, the pathophysiology of such events is complex and incompletely understood by the analysis or measurement of a single vasoactive mediator. Postoperative pulmonary hypertension represents a complex interplay between the preoperative condition of the patient (importantly age at repair, type of lesion and presence of a syndrome) and the inevitable disruption in the endocrine and vasoactive peptide milieu that results from cardiac surgery. Important contributors to a milieu of enhanced vasoconstriction are cardiopulmonary bypass, hypothermia and circulatory arrest. Residual cardiac lesions and the sequelae of the

Correspondence to: Ian Adatia, MBChB, MRCP(UK), FRCP(C), Room 3A1.44, Walter C. Mackenzie Health Sciences Center, 8440112 St., Edmonton, AB, T6G 3T7, Canada. E-mail: iadatia@ualberta.ca stress response, hypoxia, metabolic and respiratory acidosis may all contribute additional imbalances favoring pulmonary vasoconstriction. Postoperative sequelae such as right and left ventricular and atrioventricular valve dysfunction will be important in determining how well the postoperative elevation in pulmonary vascular resistance is tolerated. Currently, endothelial cell dysfunction, present preoperatively and exacerbated by perioperative influences is considered a unifying hypothesis to account for many postoperative sequelae. ${ }^{3-5}$ However, improvements in surgical and perioperative technique and perhaps most importantly the trend towards performing surgical repair early, has resulted in a marked decrease in the incidence of symptomatic postoperative pulmonary hypertension in countries with privileged referral patterns. The incidence of postoperative pulmonary hypertensive events decreased from $31 \%$ in the $1980-$ 84 era to $6.8 \%$ before the routine use of inhaled nitric oxide. ${ }^{6}$ Series reflective of contemporary practice suggest that pulmonary hypertension complicates $2.0 \%$ of patients undergoing congenital cardiac surgery with crises occurring in $0.75 \% .^{7}$ However, the mortality in those suffering a crisis remains high at $20 \%$ and pulmonary vascular disease is identified as a major contributor to hospital length of stay and need for prolonged mechanical ventilation. ${ }^{6-9}$

\section{Predicting risk factors for symptomatic postoperative pulmonary hypertension}

It is difficult to predict which patients will experience pulmonary hypertensive crises or right ventricular failure with low cardiac output postoperatively. 
Patients who experience crises usually have reactive pulmonary vascular beds. Patients dying from pulmonary arterial hypertensive crises have increased muscularization of the small pulmonary arterioles without changes of irreversible pulmonary vascular disease. ${ }^{1}$ Patients who undergo surgical repair with fixed elevations of pulmonary vascular resistance may not experience crises but are at risk of right ventricular failure especially if there is postoperative deterioration of atrioventricular valvar regurgitation and right ventricular function. Most patients with high flow, high-pressure and low pulmonary vascular resistance lesions will not require therapy for pulmonary arterial hypertension postoperatively. ${ }^{7}$ There is, therefore, considerable value in attempting to select high-risk patients for special monitoring or even prophylactic therapy. Risk stratification is mainly clinical because lung biopsy and cardiac catheterization are not performed routinely prior to cardiac surgery. Patients with clinical or echocardiographic signs of an elevated pulmonary vascular resistance may benefit from preoperative cardiac catheterization to assess risk and operability. Preoperative lung biopsy alone has a limited capacity to define operability compared with hemodynamic assessments. Patients with extracardiac syndromes (especially Down's syndrome) seem to be at increased risk of pulmonary hypertensive events. Patients with pulmonary venous or left atrial hypertension whether following pulmonary vein surgery or from left heart abnormalities (hypoplasia, mitral regurgitation or stenosis) have extremely reactive pulmonary vasculature. In general, for all lesions, early repair appears to confer benefit on postoperative pulmonary vascular complications and this applies to truncus arteriosus, atrioventricular septal defect, ventricular septal defect and transposition of the great arteries with ventricular septal defect. ${ }^{7,10,11}$ Patients with aortic origin of a pulmonary artery, truncus arteriosus and single ventricle lesions with unrestrictive pulmonary blood flow have markedly reactive pulmonary vascular beds in the postoperative period especially if intervention is delayed beyond the age of 2 months. ${ }^{10,12}$ All patients with problematic postoperative pulmonary hypertension should undergo investigation to exclude residual or overlooked left-to-right intracardiac shunts. In general, there is consensus that early repair of uncomplicated left to right shunt lesions in the first 6 months of life reduces the risk of postoperative pulmonary hypertension in patients with high-risk diagnoses. Thus a profile of a high-risk patient might be a 14-monthold child with Down's syndrome, an unbalanced atrioventricular canal defect but not sufficiently to preclude a biventricular repair. At preoperative cardiac catheterization the pulmonary vascular resistance index is calculated at 6.0 Wood units $\cdot \mathrm{m}^{2}$. The patient is reactive to inhaled nitric oxide and hyperoxia. The lowest pulmonary vascular resistance index is 1.5 Wood units $\cdot \mathrm{m}^{2}$, with a shunt of more than 5:1 from left to right. The child undergoes repair, and postoperatively there is mitral insufficiency and stenosis, and tricuspid valvar regurgitation.

Patients most at risk of pulmonary bypertensive crises who require special monitoring are older at repair, with a high degree of reactivity, with an extra cardiac syndrome, and an elevated pulmonary venous or left atrial pressure. In addition, patients with decreased right ventricular function or tricuspid valve regurgitation maybe intolerant of even mild increases in pulmonary vascular resistance and benefit from pulmonary vasodilator therapy.

Class: $I$. Level of evidence: $B$.

\section{The use of pulmonary arterial catheters}

If it is difficult to predict who will develop symptomatic postoperative pulmonary hypertension the question may be asked whether all patients should have a pulmonary arterial catheter to monitor pulmonary arterial pressure. The use of pulmonary arterial lines is associated with low morbidity particularly when used in an institution experienced with pulmonary arterial line management. The adverse event associated with a short-term pulmonary arterial line is the risk of bleeding after removal especially in the presence of elevated pulmonary arterial and right ventricular pressures. ${ }^{13}$ The risk may be mitigated by placing the pulmonary arterial line through the right atrium or muscular right ventricular infundibulum. However, the incidence of symptomatic pulmonary arterial hypertension is now so low that it may no longer be justified to place a line in all patients undergoing repair of high pressure or high flow lesions or both. Pulmonary arterial lines focus the attention of caregivers on the pulmonary arterial pressure and this may paradoxically delay progress through the cardiac intensive care unit, as there is a tendency to react to each fluctuation in pulmonary arterial pressure. However, for the evaluation of new postoperative therapies whether specific for the pulmonary vasculature or otherwise, pulmonary arterial lines are essential to provide data on cardiac output as well calculate pulmonary vascular resistance. Often the decision to place a pulmonary arterial line is made by necessity in the operating room if elevated pulmonary arterial pressures (mean pulmonary arterial pressure greater than $25 \mathrm{mmHg}$ or more than $50-60 \%$ of systemic pressure) are encountered or if there is the need for specific pulmonary vasodilator therapy to separate from cardiopulmonary bypass. Echocardiography 
accurately predicts right ventricular and pulmonary arterial pressure through interrogation of tricuspid regurgitation and pulmonary insufficiency velocities. Imaging of the right ventricle and evaluation of potential residual lesions is also useful. However, echocardiographic assessment in the sick unstable postoperative patient with limited windows is operatordependant, and while echocardiographic assessment is extremely valuable it may not be feasible in offhours or during a crisis. After the crisis has resolved pulmonary arterial pressures may be misleadingly normal. Right ventricular pressure may not predict pulmonary arterial pressure if there is obstruction of the right ventricular outflow tract or branch pulmonary artery. Nevertheless, echocardiography together with mixed venous saturation and central venous pressure monitoring are powerful tools in the assessment of pulmonary hypertensive patients.

The use of small implantable devices that monitor pulmonary arterial pressure have not been used extensively in this population. If the patient is at risk for sustained pulmonary hypertension and prolonged postoperative therapy is likely, these devices may have a place in monitoring.

Direct measurement of pulmonary artery pressure is recommended if mean pulmonary artery pressure is $>25 \mathrm{mmHg}$ (or $50-60 \%$ of systemic pressure) or specific pulmonary vasodilator therapy is used in the operating room. However, there is no evidence to suggest that direct pulmonary artery pressure measurements improve outcome.

Echocardiography together with mixed venous saturation and central venous pressure monitoring may provide adequate information for patient treatment if direct measurements are unavailable.

Class: I. Level of evidence: $C$.

\section{The management of postoperative pulmonary hypertension}

There are no clear pulmonary arterial pressure or pulmonary vascular resistance measurements that indicate a need for postoperative therapy. However, consensus would indicate that patients with postoperative pulmonary hypertension (mean pulmonary arterial pressure greater than $25 \mathrm{mmHg}$ or more than $50-60 \%$ of systemic pressure) associated with signs of low cardiac output or its surrogates are concerning and indicative of the need to consider specific therapy. Prevention of pulmonary hypertensive crises is a worthy goal of treatment but elusive because of the difficulty in predicting who will suffer a crisis and the rarity of crises in contemporary practice.

Management of symptomatic pulmonary hypertension involves avoiding or mitigating vasoconstrictive triggers and the use of pulmonary vascular specific therapies. It has been observed that pulmonary hypertensive crises may be triggered by stressful stimuli including tracheal suctioning, pain and anxiety. The use of high dose fentanyl to suppress the stress response in neonates undergoing surgery has been established in randomized controlled studies. ${ }^{14,15} \mathrm{It}$ has become common practice to use continuous fentanyl infusions with muscle relaxation through the first postoperative night. Supplemental fentanyl prior to endotracheal suctioning will suppress the pulmonary vasoconstrictor response providing suction is performed without causing hypoxia or hypercarbia.

Hypoxia is a potent pulmonary vasoconstrictor and should be avoided in high-risk patients. However, there is less evidence to suggest that hyperoxia is as potent a vasodilator as in the preoperative patient. Mechanical ventilation with high concentrations of oxygen for prolonged periods should be avoided. Avoiding hypoxia is extremely important and ventilation with supplemental oxygen is used often to prevent triggering pulmonary vasoconstriction. Acidosis, whether respiratory or metabolic, is a powerful vasoconstrictor and alkalosis is as effective a pulmonary vasodilator as inhaled nitric oxide. ${ }^{16,17}$ Hyperventilation or the infusion of sodium bicarbonate are extremely useful strategies in the immediate management of pulmonary hypertensive crises while more specific strategies are put in place. However, there are drawbacks to prolonged induction of therapeutic alkalosis. The disadvantages of prolonged high mechanical ventilator settings include pulmonary barotrauma and reduction of cardiac output especially in the face of poor right ventricular function. Infusions of sodium bicarbonate decrease cardiac output and cerebral blood flow and increase central venous pressure and systemic vascular resistance. Nevertheless, avoiding acidosis is as important as avoiding hypoxia to prevent pulmonary vasoconstriction, and most would advocate a $\mathrm{pH} \geqslant 7.4$ in patients at risk or 7.5 in refractory pulmonary arterial hypertension. In patients with a surgically created rightto-left "pop off" and hypoxemia, some would advocate adjusting the hemoglobin to a level commensurate with systemic arterial oxygen saturations.

Inhaled nitric oxide has become the accepted therapy for postoperative pulmonary arterial hypertension. Advantages of inhaled nitric oxide include the ease of delivery, minimal side effect profile and specificity for the pulmonary vascular bed. Nitric oxide is endothelial cell derived and activates guanylate cyclase to cause vascular vasodilation through a cyclic guanosine monophosphate dependant mechanism. Nitric oxide is inactivated rapidly by hemoglobin. If inhaled, nitric oxide causes selective pulmonary vasodilation because of rapid inactivation by hemoglobin before transit through the pulmonary vascular bed. Thus unlike non-specific pulmonary vasodilators, nitric oxide decreases intrapulmonary shunt fraction and will often improve systemic arterial oxygenation. 
Inhaled nitric oxide has been shown in many studies to be an effective pulmonary vasodilator in postoperative patients with congenital cardiac disease. ${ }^{3,16,18-22}$ The doses of nitric oxide have ranged from $2-80 \mathrm{ppm}^{19}$ There does not appear to be any clear benefit from doses in excess of 10-20 ppm for routine use. It is often forgotten that the measured nitric oxide is a concentration at the proximal endotracheal tube and may not reflect the dose delivered to the alveolus. However, side effects such as methemoglobinemia are rare with doses less than $80 \mathrm{ppm}$ even for prolonged periods. Nevertheless it is prudent to measure levels of methemoglobin daily while nitric oxide is administered. Commercially available delivery devices and ventilators without mechanical bellows have reduced concerns with nitric dioxide and issues surrounding gas scavenging. ${ }^{23,24}$ Thus, inhaled nitric oxide may reduce mortality after repair of atrioventricular canal defects. ${ }^{22}$ In a randomised double blind controlled trial, treatment with nitric oxide reduced pulmonary arterial hypertensive crises and shortened time to reach criteria for extubation. However, ventilator days were not significantly different, perhaps in view of the prolonged nitric oxide weaning protocol used to avoid rebound pulmonary hypertension. ${ }^{25}$ One randomized and controlled study failed to show an advantage to inhaled nitric oxide when used against a background of presumably hyperoxic alkalosis. ${ }^{26}$

Rebound pulmonary hypertension has been described upon rapid withdrawal of nitric oxide or withdrawal prior to resolution of pulmonary vascular constriction. ${ }^{27,28}$ Rebound may result in considerable hemodynamic instability, ventilation difficulty, and hypoxia and require reinstitution of inhaled nitric oxide, or adjunctive therapies such as ventilation, and hyperoxic alkalosis. The effects can be minimized by slow weaning, in particular the last $5 \mathrm{ppm}$. The need, however, for prolonged inhaled nitric oxide therapy may delay tracheal extubation, and transition to oral or intermittently inhaled pulmonary vasodilators may be considered at this point in therapy. A randomized controlled blinded study has demonstrated that oral sildenafil (a type 5 phosphodiesterase inhibitor) at $0.3-$ $0.5 \mathrm{mg} / \mathrm{kg}$ results in abolition of rebound and facilitates shorter times to extubation and intensive care stay. ${ }^{29}$ This strategy also may be useful in transitioning patients to chronic therapy. ${ }^{30}$ Despite attention to adjunctive measures and the use of inhaled nitric oxide, there are patients whose pulmonary arterial hypertension is refractory to therapy. Sildenafil intravenously or orally and inhaled Iloprost and intravenous prostacyclin may be used to augment a pulmonary vasodilator response to inhaled nitric oxide.
Drugs, which augment cardiac output as well as dilate the pulmonary vascular bed, such as milrinone, levosimendan, and nesiritide may be useful adjuncts providing the patient is tolerant of systemic vasodilation. Vasopressin is a pulmonary vasodilator and systemic vasoconstrictor, and may be useful in the management of systemic hypotension associated with pulmonary hypertension. Strategies to prevent pulmonary hypertension postoperatively by initiating therapies prior to or during cardiopulmonary bypass such as citrulline to augment nitric oxide production, sildenafil to increase cyclic guanosine monophosphate levels or endothelin receptor antagonists to diminish the effects of elevated endothelin 1 levels are promising ideas and potentially fruitful areas of research. ${ }^{31,32}$

1. Blunting the stress response with narcotics and muscle relaxation, avoiding bypoxia and acidosis and augmenting cardiac output are important adjunctive treatments for patients at risk of pulmonary bypertensive crises.

Class: $I . \quad$ Level of evidence: $B$.

2. Inhaled nitric oxide decreases pulmonary artery pressure and vascular resistance, and may prevent pulmonary bypertensive crises and shorten time to reach extubation criteria in patients with postoperative pulmonary artery hypertension. Sildenafil effectively prevents rebound pulmonary bypertension associated with withdrawal of inhaled nitric oxide therapy, and reduces mechanical ventilation and intensive care unit stay.

Class: $I$. Level of evidence: $B$.

\section{References}

1. Hopkins RA, Bull C, Haworth SG, de Leval MR, Stark J. Pulmonary hypertensive crises following surgery for congenital heart defects in young children. Eur J Cardiothorac Surg 1991; 5 : 628-634.

2. Wheller J, George BL, Mulder DG, Jamarkani JM. Diagnosis and management of postoperative pulmonary hypertensive crisis. Circulation 1979; 60: 1640-1644.

3. Wessel DL, Adatia I, Giglia TM, Thompson JE, Kulik TJ. Use of inhaled nitric oxide and acetylcholine in the evaluation of pulmonary hypertension and endothelial function after cardiopulmonary bypass. Circulation 1993; 88[part 1]: 2128-2138.

4. Komai H, Adatia I, Elliott MJ, de Leval MR, Haworth SG. Increased plasma levels of endothelin-1 after cardiopulmonary bypass in patients with pulmonary hypertension and congenital heart disease. J Thorac Cardiovasc Surg 1993; 106: 473-478.

5. Adatia I, Barrow S, Stratton P, Ritter J, Haworth S. Effect of intracardiac repair on biosynthesis of thromboxane A2 and prostacyclin in children with a left to right shunt. Br Heart J 1994; 72: 452-456.

6. Bando K, Turrentine MW, Sharp TG, et al. Pulmonary hypertension after operations for congenital heart disease: analysis of risk factors and management. J Thorac Cardiovasc Surg 1996; 112: 1600-1607; discussion 1607-1609.

7. Lindberg L, Olsson AK, Jogi P, Jonmarker C. How common is severe pulmonary hypertension after pediatric cardiac surgery? J Thorac Cardiovasc Surg 2002; 123: 1155-1163.

8. Brown KL, Ridout DA, Goldman AP, Hoskote A, Penny DJ. Risk factors for long intensive care unit stay after cardiopulmonary bypass in children. Crit Care Med 2003; 31: 28-33. 
9. Schulze-Neick I, Li J, Penny DJ, Redington AN. Pulmonary vascular resistance after cardiopulmonary bypass in infants: effect on postoperative recovery. J Thorac Cardiovasc Surg 2001; 121: 1033-1039.

10. Hanley F, Heinemann M, Jonas R, et al. Repair of truncus arteriosus in the neonate. J Thorac Cardiovasc Surg 1993; 105: 1047-1056.

11. Haworth SG. Pulmonary vascular disease in different types of congenital heart disease. Br Heart J 1984; 52: 557-571.

12. Brizard CP, Cochrane A, Austin C, Nomura F, Karl TR. Management strategy and long-term outcome for truncus arteriosus. Eur J Cardiothorac Surg 1997; 11: 687-695; discussion 695-686.

13. Flori HR, Johnson LD, Hanley FL, Fineman JR. Transthoracic intracardiac catheters in pediatric patients recovering from congenital heart defect surgery: associated complications and outcomes. Crit Care Med 2000; 28: 2997-3001.

14. Anand KJ, Hansen DD, Hickey PR. Hormonal-metabolic stress responses in neonates undergoing cardiac surgery. Anesthesiology 1990; 73: 661-670.

15. Anand KJ, Sippell WG, Aynsley-Green A. Randomised trial of fentanyl anaesthesia in preterm babies undergoing surgery: effects on the stress response. Lancet 1987; 1 (8524): 62-66.

16. Morris K, Beghetti M, Petros A, Adatia I, Bohn D. Comparison of hyperventilation and inhaled nitric oxide for pulmonary hypertension after repair of congenital heart disease. Crit Care Med 2000; 28: 2974-2978.

17. Chang AC, Zucker HA, Hickey PR, Wessel DL. Pulmonary vascular resistance in infants after cardiac surgery: role of carbon dioxide and hydrogen ion. Crit Care Med 1995; 23: 568-574.

18. Beghetti M, Habre W, Berner M. Continuous low dose inhaled nitric oxide for treatment of severe pulmonary hypertension after cardiac surgery in paediatric patients. Br Heart J 1995; 73: 65-68.

19. Miller OI, Celermeyer DS, Deanfield JE, Macrae DJ. Very low dose inhaled nitric oxide: a selective pulmonary vasodilator after operations for congenital heart disease. J Thorac Cardiovasc Surg 1994; 108: 487-494.

20. Journois D, Pouard $P$, Mauriat $P$, Malhère $T$, Vouhé $P$, Safran $D$. Inhaled nitric oxide as a therapy for pulmonary hypertension after operations for congenital heart defects. J Thorac Cardiovasc Surg 1994; 107: 1129-1135.

21. Russell IA, Zwass MS, Fineman JR, et al. The effects of inhaled nitric oxide on postoperative pulmonary hypertension in infants and children undergoing surgical repair of congenital heart disease. Anesth Analg 1998; 87: 46-51.

22. Journois D, Baufreton C, Mauriat P, Pouard P, Vouhe P, Safran D. Effects of inhaled nitric oxide administration on early postoperative mortality in patients operated for correction of atrioventricular canal defects. Chest 2005; 128: 3537-3544.

23. Wessel DL, Adatia I, Thompson JE, Hickey PR. Delivery and monitoring of inhaled nitric oxide in patients with pulmonary hypertension. Crit Care Med 1994; 22: 930-938.

24. Miller OI, Celermajer DS, Deanfield JE, Macrae DJ. Guidelines for the safe administration of inhaled nitric oxide. Arch Dis Child 1994; 70: F47-F49.

25. Miller OI, Tang SF, Keech A, Pigott NB, Beller E, Celermajer DS. Inhaled nitric oxide and prevention of pulmonary hypertension after congenital heart surgery: a randomised double-blind study. Lancet 2000; 356: 1464-1469.

26. Day RW, Hawkins JA, McGough EC, Crezee KL, Orsmond GS. Randomized controlled study of inhaled nitric oxide after operation for congenital heart disease. Ann Thorac Surg 2000; 69: 1907-1912; discussion 1913.

27. Atz AM, Adatia I, Wessel DL. Rebound pulmonary hypertension after inhalation of nitric oxide. Ann Thorac Surg 1996; 62: 1759-1764.

28. Miller OI, Tang SF, Keech A, Celermajer DS. Rebound pulmonary hypertension on withdrawal from inhaled nitric oxide. Lancet 1995; 346 (8966): 51-52.

29. Namachivayam P, Theilen U, Butt WW, Cooper SM, Penny DJ, Shekerdemian LS. Sildenafil prevents rebound pulmonary hypertension after withdrawal of nitric oxide in children. Am J Respir Crit Care Med 2006; 174: 1042-1047.

30. Humpl T, Reyes JT, Holtby H, Stephens D, Adatia I. Beneficial effect of oral sildenafil therapy on childhood pulmonary arterial hypertension: twelve-month clinical trial of a single-drug, openlabel, pilot study. Circulation 2005; 111: 3274-3280.

31. Ikonomidis JS, Hilton EJ, Payne K, et al. Selective endothelin-A receptor inhibition after cardiac surgery: a safety and feasibility study. Ann Thorac Surg 2007; 83: 2153-2160; discussion 2161.

32. Barr FE, Tirona RG, Taylor MB, et al. Pharmacokinetics and safety of intravenously administered citrulline in children undergoing congenital heart surgery: potential therapy for postoperative pulmonary hypertension. J Thorac Cardiovasc Surg 2007; 134: 319-326. 